\title{
Removal of Orange G Dye by Manganese Oxide Nanostructures
}

\author{
Raquel P. D. Victor, ${ }^{\oplus a, b}$ Luiza L. M. Fontes, ${ }^{a}$ Antônio A. Neves, ${ }^{\oplus} *, a$ \\ Maria E. L. R. de Queiroz, ${ }^{\oplus a}$ André F. de Oliveira ${ }^{a}$ and Liany D. L. Miranda ${ }^{a}$ \\ ${ }^{a}$ Departamento de Química, Universidade Federal de Viçosa, 36570-900 Viçosa-MG, Brazil \\ ${ }^{b}$ Instituto Federal de Educação, Ciência e Tecnologia do Espírito Santo, Campus Vila Velha, \\ 29106-010 Vila Velha-ES, Brazil
}

\begin{abstract}
Two types of manganese oxide were investigated for the removal/degradation of Orange $\mathrm{G}$ (OG) dye in aqueous solution. One manganese oxide (pyrolusite) was obtained commercially and the other (birnessite) was prepared according to the polyol method by means of the oxidation of $\mathrm{Mn}^{\text {II }}$ hydroxide by $\mathrm{H}_{2} \mathrm{O}_{2}$. Both materials were characterized by X-ray diffraction (XRD), infrared spectroscopy (IR), scanning electron microscopy (SEM), and nitrogen adsorption/desorption at $77 \mathrm{~K}$. The effects of agitation time, $\mathrm{pH}$, and $\mathrm{MnO}_{2}$ dose on the degradation of OG by the birnessite and pyrolusite were evaluated. Approximately 90 and $99 \%$ decoloration of OG $\left(10 \mathrm{mg} \mathrm{L}^{-1}\right)$ was obtained after $30 \mathrm{~min}$ of stirring with $0.20 \mathrm{~g} \mathrm{~L}^{-1}$ of birnessite or pyrolusite, respectively. The decoloration and increased intensity of absorbance bands in the UV-visible spectrum were indicative of a degradation process that followed pseudo-first order kinetics. The findings demonstrated the high efficiency of different types of manganese oxides for removal of this organic pollutant from waters.
\end{abstract}

Keywords: birnessite, pyrolusite, degradation, azo dye

\section{Introduction}

Manganese oxides (MOs) are composed mainly of octahedral $\mathrm{MnO}_{6}$ units connected by their vertices and/or edges. ${ }^{1}$ When the chains are bound by the shared vertices, a one-dimensional tunnel structure is formed, while sharing of the edges of the $\mathrm{MnO}_{6}$ octahedra results in a layered structure. $^{2}$

Birnessite is a type of manganese oxide with layered structure, containing manganese(III) and manganese(IV) in the $\mathrm{MnO}_{6}$ octahedra. Alkali cations and water molecules separate these layers by about $7 \AA{ }^{3}$ The interlamellar cations are responsible for electrostatic attraction of the lamellae, which provides electroneutrality. ${ }^{4}$ This phyllomanganate is found in the clay fraction of the soil, as well as in sediments and manganese nodules at the bottom of the oceans. ${ }^{5-7}$ Although the ores are naturally abundant, the MOs derived from them present little uniformity and low reproducibility, which hinders their practical application. ${ }^{7,8}$ For this reason, the production of synthetic birnessites has attracted attention due to their easy preparation and functionalization, as well their inherent homogeneity. ${ }^{9,10}$

*e-mail: aneves@ufv.br
The most common methods employed for birnessite synthesis involve the oxidation of manganese(II) hydroxide or the reduction of potassium permanganate, using a variety of oxidizing or reducing agents. ${ }^{11}$ According to McKenzie, ${ }^{11}$ the synthesis of birnessite by the reduction of $\mathrm{MnO}_{4}^{-}$in the presence of $\mathrm{HCl}$ produces brown nanoparticles. However, Cheney et al., ${ }^{3}$ in reproducing the method, showed that black birnessite nanoparticles were obtained by changing the agitation from manual to mechanical. Cheney et al. ${ }^{12}$ reported the conversion of brown birnessite produced by the classical McKenzie ${ }^{11}$ method into black birnessite by a simple sequence of physical treatments involving aging, freezing, and lyophilization.

Synthetic birnessites usually present points of zero charge $\left(\mathrm{pH}_{\mathrm{PZC}}\right)$ in the range 1.5-7.3, , ,13,14 surface areas of 10-180 $\mathrm{m}^{2} \mathrm{~g}^{-1},{ }^{9,12,15-18}$ and cation exchange capacities of $1.8-2.47 \mathrm{mmol}_{\mathrm{c}} \mathrm{g}^{-1} \cdot{ }^{15,17}$

Due to the presence of interlamellar cations, cationic exchange in birnessites occurs without causing structural change. ${ }^{2}$ Moreover, this oxide presents high reactivity for the degradation of organic compounds. ${ }^{19-21}$ Consequently, it is considered an important oxidant.

Manganese oxides have been demonstrated to provide rapid and efficient removal/degradation of different 
pollutants present in aqueous systems, including dyes, ${ }^{4,9,18,22}$ ions, ${ }^{14,17,23}$ drugs ${ }^{7,24}$ and pesticides. ${ }^{7,21,24}$

This study reports the removal/degradation of Orange $\mathrm{G}(\mathrm{OG})$ dye in aqueous solution by manganese oxides. This azo dye is widely used in the dyeing of fabrics. In addition to aesthetic problems, textile industry effluents containing azo dyes can present mutagenicity, carcinogenicity, and low biodegradability characteristics that have led them to be considered an environmental problem. ${ }^{25}$ In the literature, researches involving the removal of $\mathrm{OG}$ from water by ultrasound/ $/ \mathrm{TiO}_{2}$ processes, ${ }^{26}$ ultrasound/Al, ${ }^{27} \mathrm{UV} / \mathrm{TiO}_{2}{ }^{28}$ and $\mathrm{Sn}^{\mathrm{IV}} / \mathrm{TiO}_{2}$ /activated charcoal $^{29}$ are reported, but no work was found involving its removal by manganese oxides.

\section{Experimental}

\section{Standards and reagents}

Ethylene glycol, sodium hydroxide, manganese(II) chloride tetrahydrate $\left(\mathrm{MnCl}_{2} \cdot 4 \mathrm{H}_{2} \mathrm{O}\right)$, and polyvinylpyrrolidone (PVP), all with purity greater than $90 \%$, were purchased from Sigma-Aldrich (Steinheim, Germany). Hydrogen peroxide $\left(29 \% \mathrm{~m} \mathrm{~m}^{-1}\right)$ and analytical grade manganese(IV) oxide were obtained from Synth (São Paulo, Brazil) and Dynamics (São Paulo, Brazil), respectively. Solutions of $\mathrm{H}_{2} \mathrm{SO}_{4}$ and $\mathrm{NaOH}$ were used for $\mathrm{pH}$ adjustment. All reagents were used without any further purification.

The Orange $\mathrm{G}$ dye employed as a model substance in this study was purchased from BDH Chemicals Ltd. (Poole, England) and was used in aqueous solution $\left(10 \mathrm{mg} \mathrm{L}^{-1}\right)$.

\section{Preparation of birnessite-type manganese oxide $\left(\delta-\mathrm{MnO}_{2}\right)$}

The birnessite was prepared by the method described by Zhou et al. ${ }^{9}$ with modifications. This procedure consisted of adding $90 \mathrm{~mL}$ of ethylene glycol, $2.4 \mathrm{~g}$ $\left(0.67 \mathrm{~mol} \mathrm{~L}^{-1}\right)$ of $\mathrm{NaOH}, 0.5 \mathrm{~g}$ of PVP, and $2.97 \mathrm{~g}$ $\left(0.17 \mathrm{~mol} \mathrm{~L}^{-1}\right)$ of $\mathrm{MnCl}_{2} \cdot 4 \mathrm{H}_{2} \mathrm{O}$ to a three-neck round bottom flask, in this order, under vigorous stirring. The temperature was then increased to $40{ }^{\circ} \mathrm{C}$ (obtaining a bright red solution) and $10 \mathrm{~mL}$ of $\mathrm{H}_{2} \mathrm{O}_{2}\left(29 \% \mathrm{~m} \mathrm{~m}^{-1}\right)$ was added. The temperature was increased to approximately $100{ }^{\circ} \mathrm{C}$ and the mixture was kept under reflux, with magnetic stirring, for an additional hour. After this time, the reaction was stopped, and the mixture was cooled to room temperature. The reaction product, a dark precipitate of birnessite, was separated by centrifugation and washed several times with ethanol. This precipitate was dried in an oven for approximately $8 \mathrm{~h}$ at $40{ }^{\circ} \mathrm{C}$ and was then triturated in an agate mortar.
The influence of temperature $\left(40\right.$ and $\left.70{ }^{\circ} \mathrm{C}\right)$ and the rate of addition of hydrogen peroxide to the reaction medium (dropwise and continuously) were evaluated using a univariate procedure.

\section{Characterization of the manganese oxides}

The synthesized and commercial manganese oxides were characterized by X-ray diffractometry (XRD), infrared spectroscopy (IR), scanning electron microscopy (SEM), and nitrogen adsorption/desorption at $77 \mathrm{~K}$.

The XRD analyses were performed using a Bruker D8 Discover DaVinci diffractometer with $\mathrm{CuK} \alpha$ radiation $(\lambda=1.54 \AA ; 40 \mathrm{kV} ; 40 \mathrm{~mA}), \mathrm{Ni}$ filter, and $2 \theta$ scan from $5^{\circ}$ to $70^{\circ}$. The samples were prepared on a glass slide by mixing the oxide with ethanol to form a slurry.

Infrared attenuated total reflectance (IR-ATR) spectra were obtained using a Varian 660-IR infrared spectrophotometer equipped with a PIKE GladiATR attenuated reflectance accessory. A blank spectrum was obtained in the absence of the sample, after which each sample was placed directly on the ATR crystal and spectra were acquired at $400-4000 \mathrm{~cm}^{-1}$.

SEM analysis of particle morphology was performed using a JEOL model JSM-6010A electron microscope with a tungsten filament, at an acceleration voltage of up to $20 \mathrm{kV}$. Double-sided adhesive tape was used to attach the samples to aluminum stubs covered with a thin layer of conductive glue. The stubs were then coated with gold using a metallizer.

The specific surface area was determined according to the Brunauer-Emmett-Teller (BET) method. Measurements were performed with a surface analyzer (Quantchrome), using $0.1 \mathrm{~g}$ of sample and nitrogen adsorption/desorption at $77 \mathrm{~K}$.

Application of manganese oxides in the removal of Orange $G$ from water

The experiments to determine the influence of the variables agitation time, nanocomposite dose, and $\mathrm{pH}$ of the solution on the removal/degradation of Orange $G$ present in water were performed at room temperature using a $500 \mathrm{~mL}$ glass Erlenmeyer flask as the reactor, protected from light.

The effect of stirring time was evaluated by adding $50 \mathrm{mg}$ of the synthesized or commercial oxide to $300 \mathrm{~mL}$ of the aqueous $10 \mathrm{mg} \mathrm{L}^{-1}$ dye solution at $\mathrm{pH} 2$ (previously adjusted with dilute $\mathrm{H}_{2} \mathrm{SO}_{4}$ solution). The mixture was agitated for 90 min using a magnetic stirrer. Aliquots $(3 \mathrm{~mL})$ were collected at regular 15 min intervals and centrifuged for $10 \mathrm{~min}$ at $8000 \mathrm{rpm}$. The residual concentration of the 
dye was determined by analyzing the supernatant using a Hitachi U-2000 UV-visible spectrophotometer fitted with a quartz cuvette $(1 \mathrm{~cm}$ optical path length). The tests to determine the influence of $\mathrm{pH}$ were performed following the same procedure, with the dye solution at initial $\mathrm{pH}$ values of 2.0, 4.5, and 8.0.

In the study of the effect of the dose of synthesized or commercial $\mathrm{MnO}_{2}$ on dye removal/degradation, doses of $0.30,0.20$, and $0.08 \mathrm{~g} \mathrm{~L}^{-1}$ were used at the optimum $\mathrm{pH}$, following the procedure described above.

Each experiment was performed in duplicate. The removal efficiency was calculated as follows:

$\operatorname{Re} \operatorname{moval}(\%)=\frac{\mathrm{A}_{\mathrm{i}}-\mathrm{A}_{\mathrm{t}}}{\mathrm{A}_{\mathrm{i}}} 100$

where $A_{i}$ and $A_{t}$ are the absorbance values at the wavelength of maximum absorption of the dye $(483 \mathrm{~nm})$ at the initial time and after different times, respectively. Distilled water samples with $\mathrm{pH}$ adjusted to each value studied were used as blanks in the spectrophotometric analyses.

\section{Results and Discussion}

Birnessites of two different colors (brown and black) were obtained in this work. The temperature (40 or $\left.70{ }^{\circ} \mathrm{C}\right)$ at which the $\mathrm{H}_{2} \mathrm{O}_{2}\left(29 \% \mathrm{~m} \mathrm{~m}^{-1}\right)$ was added to the reaction medium did not influence the color, while the slow addition (dropwise) of hydrogen peroxide favored a black precipitate. In addition, the brown birnessite could be converted to black birnessite by a simple physical treatment involving maceration and drying.

The two birnessites (black and brown) were characterized in order to investigate their differences and similarities and were compared with a commercial manganese oxide.

\section{Characterization of the manganese oxides}

\section{X-ray diffractometry}

The X-ray diffractograms obtained for the black and brown precipitates produced in this work are presented in Figures 1a and $1 \mathrm{~b}$, respectively. Both samples presented diffraction peaks at approximately 7.4, 3.6, 2.5, and $1.4 \AA$ (interplanar distances, d). All the peaks were broad and of low intensity, indicative of the presence of very small and/or poorly crystallized particles. ${ }^{8,21}$ These results were similar to those reported for lamellar phases of natural birnessite ${ }^{7,24}$ and synthetic black or brown forms. ${ }^{3,9,12}$ Peaks at $2 \theta$ smaller than $20^{\circ}$ were related to the distance between lamellae (also termed basal spacing). This feature favors the use of these materials in ion exchange and intercalation applications..$^{30}$
On the other hand, the commercial $\mathrm{MnO}_{2}$ presented a diffractogram (Figure 1c) with peaks at interplanar distances (d) of 3.13, 2.42, 2.21, 1.97, 1.62, and $1.56 \AA$. These peaks are characteristic of $\beta-\mathrm{MnO}_{2}$ crystals, as reported previously for synthetic pyrolusite. ${ }^{31}$

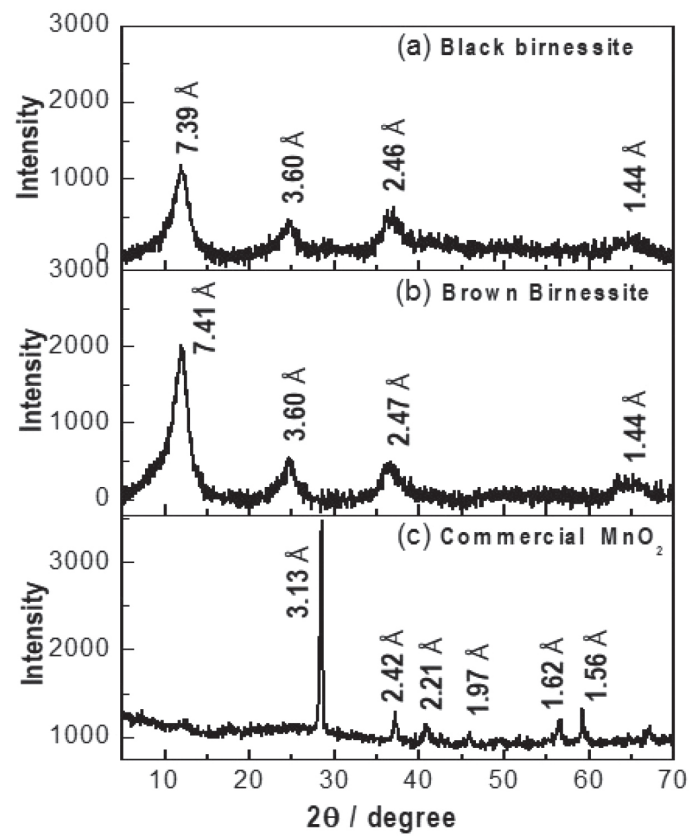

Figure 1. X-ray diffractograms of the manganese oxides: (a) black birnessite; (b) brown birnessite; and (c) pyrolusite (commercial $\mathrm{MnO}_{2}$ ).

The XRD analyses also enabled estimation of the mean particle sizes of the manganese oxides, using the Scherrer equation:

$\mathrm{D}_{\mathrm{m}}=\frac{\mathrm{k} \lambda}{\beta \cos \theta}$

where $D_{m}$ is the mean particle diameter; $\lambda$ is the Cu radiation wavelength (1.541 $\AA$ ), and $\beta$ and $\theta$ are the width at half height and the diffraction angle of the highest intensity peak, respectively. The constant $\mathrm{k}$ is a proportionality constant that depends on the shape of the particles. The synthesized birnessites and the commercial manganese oxide were considered to consist of spherical particles, with $\mathrm{k}=0.9 .^{32,33}$ The $\mathrm{D}_{\mathrm{m}}$ values obtained using this equation only estimated the particle size, but it was possible to relate them to the surface areas of the materials. The mean diameters and surface areas determined by the BET method are shown in Table 1.

The synthesized birnessites presented surface areas that were around 3-fold higher than reported by Zhou et al., and those found elsewhere for birnessites produced by other methods, where values ranged from 10 to $60 \mathrm{~m}^{2} \mathrm{~g}^{-1} \cdot{ }^{12,17,34}$ According to Wang et al., ${ }^{16}$ strong oxidants such as 
Table 1. Mean diameters and surface areas of the manganese oxides studied

\begin{tabular}{lcccc}
\hline Type of $\mathrm{MnO}_{2}$ & $\beta / \mathrm{rad}$ & $\theta /$ degree & $\mathrm{D}_{\mathrm{m}} / \AA$ & $\mathrm{SA} /\left(\mathrm{m}^{2} \mathrm{~g}^{-1}\right)$ \\
\hline Birnessite (black) & 0.028 & 5.98 & 50 & 153.9 \\
Birnessite (brown) & 0.027 & 5.97 & 52 & 125.3 \\
Pyrolusite & 0.011 & 14.2 & 130 & 10.8 \\
\hline
\end{tabular}

$\beta$ : width at half height of the highest intensity peak; $\theta$ : diffraction angle of the highest intensity peak; $\mathrm{D}_{\mathrm{m}}$ : mean diameter; $\mathrm{SA}$ : surface area.

$\mathrm{H}_{2} \mathrm{O}_{2}$ and $\mathrm{K}_{2} \mathrm{~S}_{2} \mathrm{O}_{8}$ rapidly oxidize bivalent manganese to generate a pure phase of $\delta-\mathrm{MnO}_{2}$ with a surface area of up to $150 \mathrm{~m}^{2} \mathrm{~g}^{-1}$.

The surface areas of the synthesized birnessites were in agreement with the average crystal size obtained using the Scherrer equation. A very small surface area was observed for the commercial $\mathrm{MnO}_{2}$, possibly due to a predominance of macropores that were not measured by the method employed. As pointed out by Tagliaferro et al.,$^{30}$ the gas adsorption technique only detects the presence of micropores and mesopores in the materials, while the presence of macropores is not considered in the calculation of the specific surface area by the BET method.

\section{IR-ATR spectroscopy}

The infrared spectra of the black and brown birnessites revealed residues of the synthesis reagents on the surfaces of the materials, since functional groups were identified that were not characteristic of birnessite. These impurities were removed by washing thoroughly with ethanol, resulting in the pure spectra shown in Figure 2. In the birnessite spectra, the bands located at 3310 and $1639 \mathrm{~cm}^{-1}$ (black birnessite) and at 3297 and $1640 \mathrm{~cm}^{-1}$ (brown birnessite) could be attributed to stretching vibrations of the $-\mathrm{OH}$ group of water molecules. The first broad band corresponded to water adsorbed on the birnessite, while the second band corresponded to less ordered water located within the layers. ${ }^{7,24}$ The bands observed at 467 and $466 \mathrm{~cm}^{-1}$ (Figure 2) were attributed to the stretching of the $\mathrm{Mn}-\mathrm{O}$ bonds in the octahedral layers of the black and brown birnessite and commercial pyrolusite structures. $\mathrm{Mn}-\mathrm{O}$ stretching vibrations occurred in the region from 450 to $800 \mathrm{~cm}^{-1} \cdot 2,17,23$

\section{Scanning electron microscopy}

The SEM image for the black birnessite (Figure 3a) showed that this material was composed of a cluster of randomly arranged nanosheets. The brown birnessite (Figure $3 b$ ) presented as a cloud of agglomerated and irregular nanoparticles, while the image for the commercial

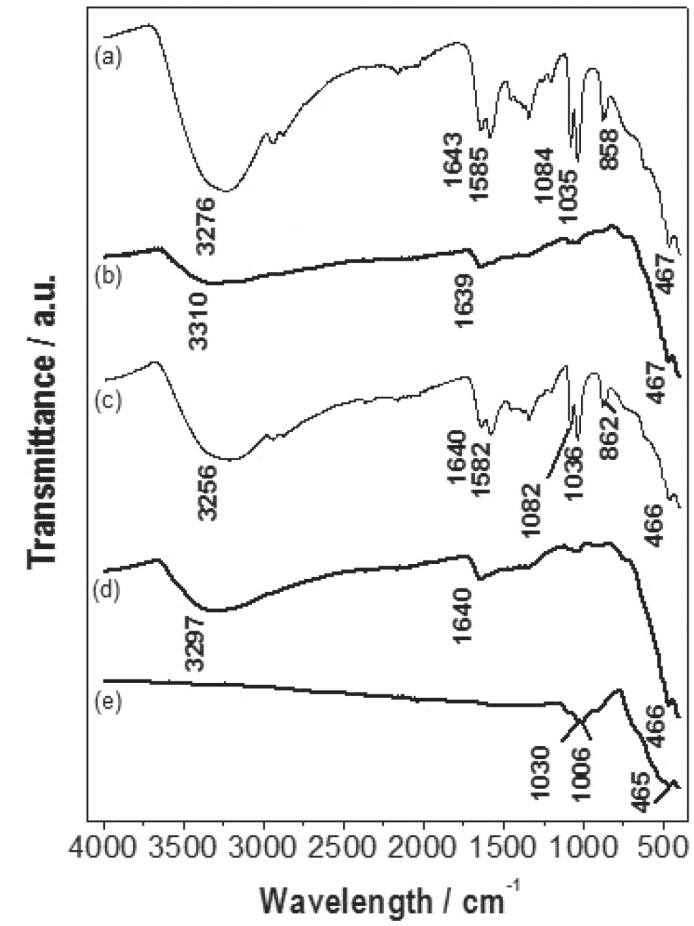

Figure 2. IR-ATR spectra of the birnessite (black and brown) and pyrolusite (commercial $\mathrm{MnO}_{2}$ ) samples. (a) Black birnessite + synthetic waste; (b) black birnessite; (c) brown birnessite + synthetic waste; (d) brown birnessite; (e) commercial $\mathrm{MnO}_{2}$.

$\mathrm{MnO}_{2}$ (Figure 3c) showed unequally distributed plaques. The micrographs revealed differences in the forms of the black and brown birnessites and of the commercial product, with changes in the rate of addition of hydrogen peroxide during the synthesis causing differences in the morphologies of the birnessites.

Application of manganese oxides in the removal of Orange $G$ dye in aqueous solution

Influence of stirring time on the efficiency of removal of Orange $G$ dye in aqueous solution

Figures $4 a-4 c$ show the UV-Vis spectra of the solution of Orange $\mathrm{G}$ dye $\left(10 \mathrm{mg} \mathrm{L}^{-1}\right)$ at $\mathrm{pH} 2$, as a function of the time of treatment with the birnessite and pyrolusite manganese oxides.

Before addition of the manganese oxides, the spectrum of the Orange $\mathrm{G}$ dye showed a major band in the visible region, with maximum absorption at $483 \mathrm{~nm}\left(\lambda_{\max }\right)$ and a shoulder at $405 \mathrm{~nm}$, due to azo-hydrazone tautomerization of the azo $(-\mathrm{N}=\mathrm{N}-)$ bond. ${ }^{35,36}$ Two other bands, at 329 and $248 \mathrm{~nm}$, were associated with naphthalene and benzene rings, respectively. ${ }^{35-37}$

When black birnessite was used to remove Orange $G$ dye from aqueous solution (Figure 4a), the intensities of the bands at 483 and $329 \mathrm{~nm}$ decreased to near-zero with 

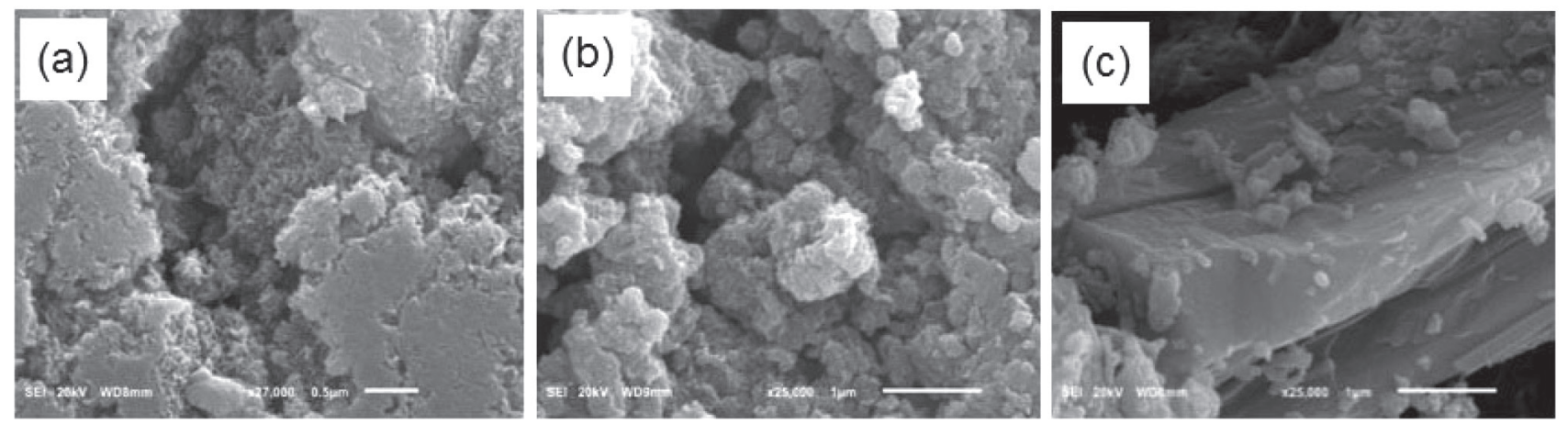

Figure 3. Images obtained by SEM for (a) black birnessite; (b) brown birnessite; and (c) pyrolusite (commercial $\mathrm{MnO}_{2}$ ).
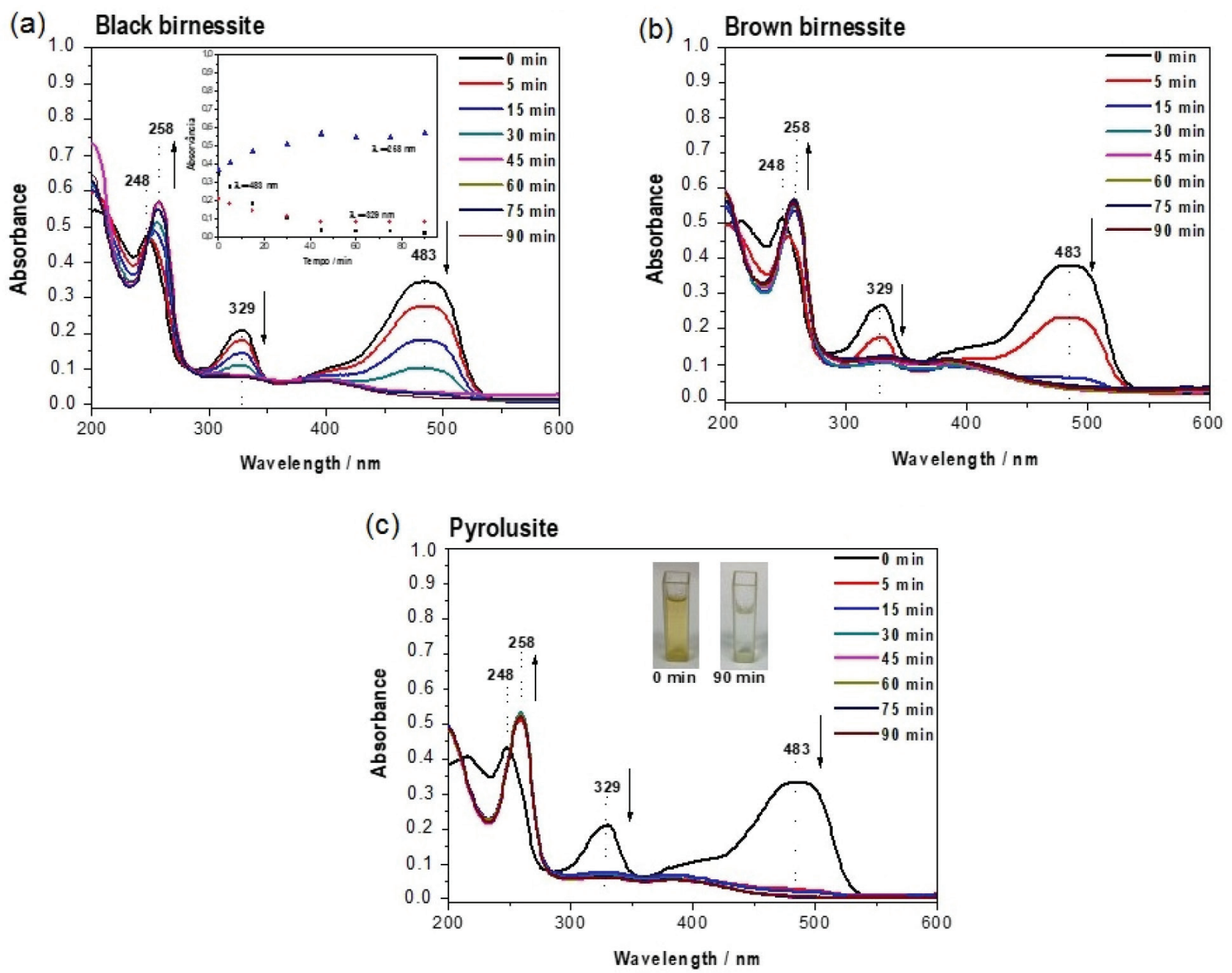

Figure 4. UV-Vis spectra of Orange $\mathrm{G}$ in aqueous solution ( $\mathrm{pH}$ 2), obtained at different times during the degradation processes using (a) black birnessite; (b) brown birnessite; and (c) pyrolusite (the inset shows images of the solution before and after treatment).

increasing stirring time. The band at $248 \mathrm{~nm}$ shifted to $258 \mathrm{~nm}$ and increased in intensity as the bands at 483 and $329 \mathrm{~nm}$ decreased in intensity, as can be seen in the detailed analysis. This behavior was indicative of degradation of the initial compound and the formation of degradation products associated with the appearance of new bands in the region from 248 to $258 \mathrm{~nm}$. The same features were observed using the brown birnessite and the pyrolusite (Figures $4 \mathrm{~b}$ and $4 \mathrm{c}$, respectively).

Monitoring of the decrease in absorbance at $483 \mathrm{~nm}$ showed that the OG dye was decolored by between 90 and $100 \%$ after 45 min of contact with the three oxides evaluated. The decoloration of the solution (Figure 4c) could be explained by cleavage of the $-\mathrm{N}=\mathrm{N}-$ double bond, which 
is the characteristic group responsible for the color of azo dyes including Orange $\mathrm{G} .{ }^{38}$ The disappearance of the band at $329 \mathrm{~nm}$ with increasing reaction time could be explained by fragmentation of the aromatic anion bonds due to oxidation. ${ }^{39}$ According to Cai et al. ${ }^{40}$ thirteen possible degradation products can be formed due to oxidation processes during OG degradation. Each of these can shift the absorption peak.

The intensity of agitation influenced the time required to remove the color. In the tests without birnessite, the OG spectra remained practically unaltered. The results indicated that the three oxides presented good efficiency for the decoloration of OG dye in water, with brown birnessite and pyrolusite removing the dye more rapidly, compared to black birnessite. The quantities of manganese(II), (III) and (IV) present in each type of manganese oxide have not been determined. However, considering that a higher amount of $\mathrm{Mn}^{\mathrm{IV}}$ increases the oxidation capacity of manganese oxide, ${ }^{22}$ this may possibly be the reason for the difference in behavior of the evaluated oxides. In the remaining assays, it was therefore decided to use only brown birnessite and pyrolusite.

Zhou et al. ${ }^{9}$ and Zhou et al. ${ }^{10}$ observed rapid removal of the dyes Ponceau 2R and methyl orange, respectively, using birnessite. In the case of Ponceau 2R, 95\% decoloration was achieved after $10 \mathrm{~min}$ of stirring the solution (at $\mathrm{pH} 1.7$ ) with birnessite. For methyl orange (at $\mathrm{pH} 1.7$ ), the same percentage of decoloration was achieved after $5 \mathrm{~min}$ of contact between the dye and the oxide.

Influence of solution $\mathrm{pH}$ on the efficiency of removal of Orange $\mathrm{G}$ in aqueous solution by the manganese oxides

The initial $\mathrm{pH}$ of the OG solution was adjusted to values of 2, 4.5, and 8.0 in order to evaluate the effect of this parameter on the rate of decoloration of the dye in the presence of the manganese oxides. The results are shown in Figure 5.

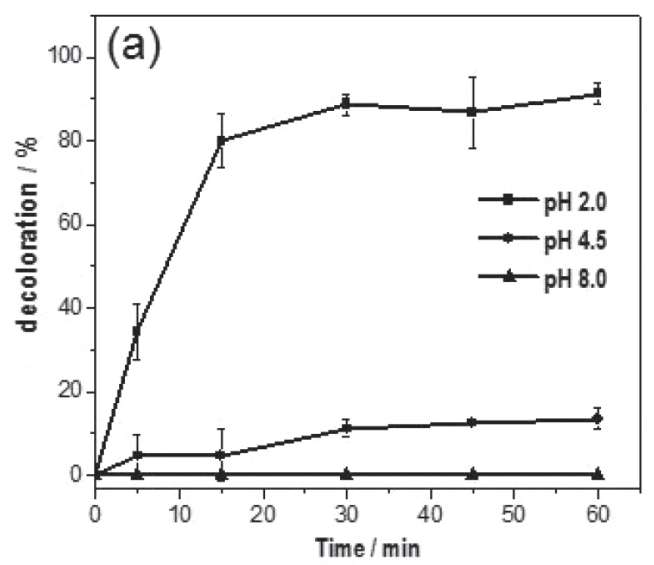

It can be seen from Figures $5 \mathrm{a}$ and $5 \mathrm{~b}$ that the percentage decoloration of OG was strongly influenced by the initial $\mathrm{pH}$ of the solution, with a marked decrease in decoloration as the initial $\mathrm{pH}$ increased. In basic media, no removal was observed for either of the manganese oxides. At $\mathrm{pH} 4.5,13$ and $0 \%$ decoloration of OG were obtained after 60 min of reaction with the brown birnessite and the pyrolusite, respectively. At $\mathrm{pH} 2$, the $\mathrm{OG}$ decoloration percentages were 90 and $99 \%$ after 30 min of reaction with the brown birnessite and the pyrolusite, respectively. Cai et $a l .{ }^{27}$ treated with an ultrasound (US) a solution of $\mathrm{OG}$ of initial concentration of $10 \mathrm{mg} \mathrm{L}^{-1}$, initial of pH 3.0 obtained, after $180 \mathrm{~min}$, a dye decoloration rate much lower than that obtained in our study $(37 \%)$. The US combination with $\mathrm{Al}$ powder and decrease in $\mathrm{pH}$ ( $\mathrm{pH} 2$ ) resulted in $98.8 \%$ decoloration after 120 min of treatment. According to Sun et al. ${ }^{29} 99.1 \%$ degradation of OG was achieved by using $\mathrm{H}_{2} \mathrm{O}_{2}$ and $\mathrm{Sn}^{\mathrm{IV}} / \mathrm{TiO}_{2}$ after $60 \mathrm{~min}$ of reaction at $\mathrm{pH} 2$. Both researchers achieved high percentages of OG decoloration after a much longer time observed in our laboratory. In addition, these results were only possible after the combination of organic pollutant treatment processes.

In order to elucidate the relationship between $\mathrm{pH}$ and the dye decoloration process, the $\mathrm{pH}_{\mathrm{PZC}}$ values of both oxides (brown birnessite and pyrolusite) were determined according to the method described by Saha and Pal. ${ }^{41} \mathrm{The}_{\mathrm{pH}} \mathrm{PZC}_{\text {value }}$ obtained for the brown birnessite was 7.7, in agreement with the value reported by Matern and Mansfeldt. ${ }^{14} \mathrm{~A} \mathrm{pH}_{\mathrm{PZC}}$ value of 7.3 was obtained for the pyrolusite.

These results suggested that the adsorption of Orange $G$ by electrostatic interaction with the manganese oxides was negligible, since slight or no removal was observed at $\mathrm{pH}$ 4.5. Therefore, the positively charged surfaces of the oxides at $\mathrm{pH}$ values below $\mathrm{pH}_{\mathrm{PZC}}(\mathrm{pH}<7)$ did not show any substantial attraction for the negatively charged dye species

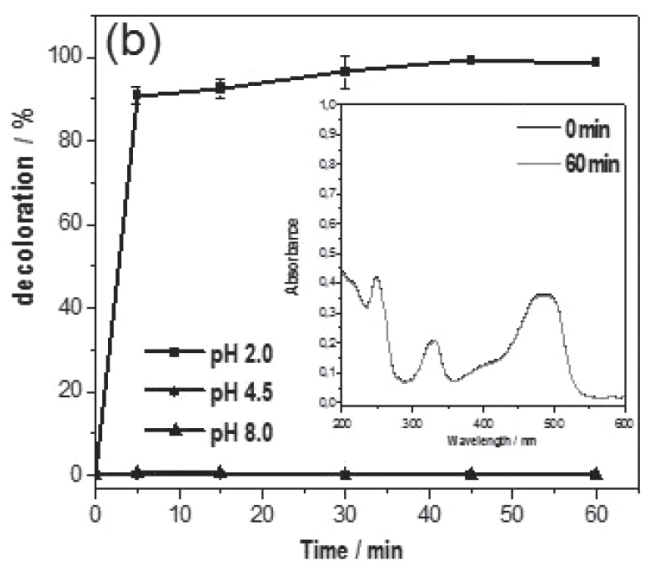

Figure 5. Effect of $\mathrm{pH}$ on the percentage decoloration of Orange $\mathrm{G}$ using (a) brown birnessite and (b) pyrolusite (in detail: UV-Vis spectra of Orange G in aqueous solution ( $\mathrm{pH}$ 2) after 0 and 60 min stirring without $\mathrm{MnO}_{2}$ ). Conditions: $300 \mathrm{~mL}$ of $10 \mathrm{mg} \mathrm{L}^{-1} \mathrm{OG}$ solution; $50 \mathrm{mg}$ of brown birnessite or pyrolusite. 
$\left(\mathrm{p} K_{\mathrm{a}}=1.0\right)$ that predominated at this $\mathrm{pH} \cdot{ }^{25,39}$ The minor influence of adsorption on the dye decoloration process was confirmed by the results for pyrolusite, which despite a low surface area showed high efficiency in the removal of Orange $\mathrm{G}$ from aqueous solution.

At lower $\mathrm{pH}$, crystals with a layered structure (such as birnessite) show poor stability, which is beneficial for the redox reaction between $\mathrm{Mn}^{\mathrm{IV}} / \mathrm{Mn}^{\mathrm{III}}$ and Orange G. ${ }^{17}$ This suggests that the degradation of Orange $\mathrm{G}$ occurred by reduction of $\mathrm{Mn}^{\mathrm{IV}} / \mathrm{Mn}^{\mathrm{III}}$ and oxidation of the dye, without any significant influence of the surface area of the oxide.

At lower $\mathrm{pH}$ (below 7), the degradation could occur by the generation of hydroxyl radicals $(\mathrm{OH} \cdot)$ and a change in the oxidation state of manganese in aqueous solution. At $\mathrm{pH}<7, \mathrm{Mn}^{\mathrm{IV}}$ is easily converted to $\mathrm{Mn}^{\mathrm{II}}$, producing hydroxyl radicals according to the following reaction:

$$
\begin{aligned}
\mathrm{Mn}^{\mathrm{IV}} \mathrm{O}_{2(\mathrm{~s})}+4 \mathrm{H}^{+}+2 \mathrm{e}^{-} \leftrightarrow & \mathrm{Mn}^{2+}{ }_{(\mathrm{aq})}+2 \mathrm{OH} \cdot+\mathrm{H}_{2} \mathrm{O} \\
& \left(\mathrm{E}^{0}=+1.23 \mathrm{~V}\right)
\end{aligned}
$$

The formation of hydroxyl radicals can be explained by the generation of a precursor complex, $\mathrm{Mn}^{\mathrm{IV}}-\mathrm{HOH}$, followed by electron transfer to reduce $\mathrm{Mn}^{\mathrm{IV}}$ to $\mathrm{Mn}^{\mathrm{II}}$, with release of hydroxyl radicals, according to the following reaction scheme (equations 4-7): ${ }^{42,43}$

Formation of the precursor complex:

$\mathrm{Mn}^{\mathrm{IV}}+2 \mathrm{HOH} \leftrightarrow\left(\mathrm{Mn}^{\mathrm{IV}}, 2 \mathrm{HOH}\right)$

Electron transfer:

$\left(\mathrm{Mn}^{\mathrm{IV}}, 2 \mathrm{HOH}\right) \leftrightarrow\left(\mathrm{Mn}^{\mathrm{II}}, 2 \mathrm{OH} \cdot\right)+2 \mathrm{H}^{+}$

Release of hydroxyl radicals:

$\left(\mathrm{Mn}^{\mathrm{II}}, 2 \mathrm{OH} \cdot\right)+2 \mathrm{H}^{+} \leftrightarrow \mathrm{Mn}^{\mathrm{II}}+2 \mathrm{OH}$

Release of reduced $\mathrm{Mn}^{\mathrm{II}}: \mathrm{Mn}^{\mathrm{IV}} \leftrightarrow \mathrm{Mn}^{2+}{ }_{\text {(aq) }}$

The hydroxyl radicals generated are able to oxidize the toxic organic dye and produce nontoxic inorganic products, with the formation of several intermediates, as follows: ${ }^{42,43}$

$\mathrm{OH} \cdot+$ toxic organic dye $\rightarrow$ organic intermediates $\rightarrow$

$\mathrm{CO}_{2}+\mathrm{H}_{2} \mathrm{O}+$ nontoxic degraded inorganic

In order to verify the contribution of the $\cdot \mathrm{OH}$ radicals in the decoloration of the OG solution, an experiment with the presence of tert-butyl alcohol was carried out. According to Ismail et al.,$^{44}$ the tert-butyl alcohol acts as an $\cdot \mathrm{OH}$ trap and can be used to confirm its involvement in the removal of the organic pollutant. It can be observed in Figure 6 that the presence of tert-butyl alcohol did not affect the effect of birnessite-type manganese oxide on dye decoloration, whereas for pyrolusite decoloration was reduced from 98 to $47 \%$. However, the presence of $\mathrm{NO}_{2}^{-}$ions inhibited almost $100 \%$ the decoloration for both oxides. Although $\mathrm{NO}_{2}^{-}$ ions may also act as $\cdot \mathrm{OH}$ scavengers under the conditions studied, it is believed that these ions inhibited the oxidative degradation reaction of the dye due to their participation in the redox reaction in place of the organic pollutant. Thus, it is suggested that the evaluated manganese oxides acted as oxidants of the studied dye.

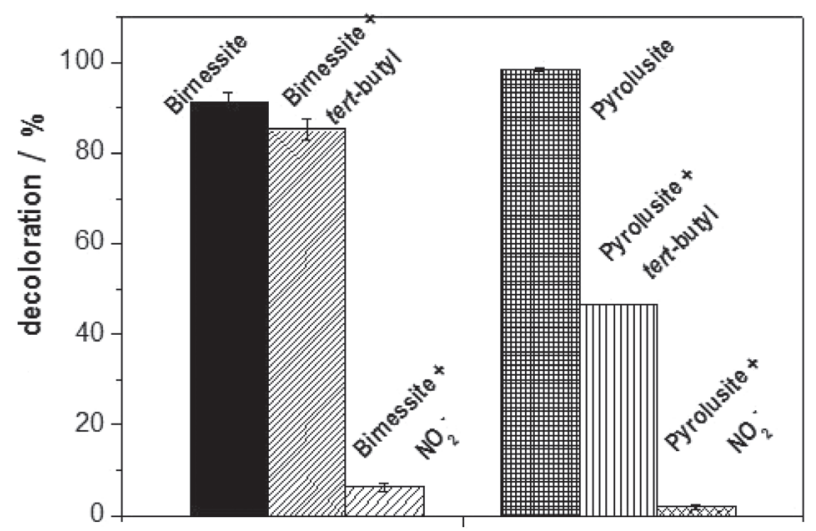

Figure 6. Percentage of decoloration of Orange $G$ in the presence of tert-butyl alcohol and $\mathrm{NO}_{2}^{-}$ions. Conditions: $300 \mathrm{~mL}$ of $10 \mathrm{mg} \mathrm{L}^{-1} \mathrm{OG}$ solution, $50 \mathrm{mg}$ of brown birnessite or pyrolusite, $60 \mathrm{~min}$ of stirring.

It should be noted that the theoretical removal capacity was approximately $50 \mathrm{mg}$ of Orange $\mathrm{G}$ per $\mathrm{g}$ of birnessite (or pyrolusite). Qin et al. ${ }^{18}$ used the same ratio for the degradation of rhodamine B by birnessite, while Saha and $\mathrm{Pal}^{41}$ used $60 \mathrm{mg}$ of malachite green per $\mathrm{g}$ of $\mathrm{MnO}_{2}$ synthesized.

These results are similar to those obtained by Zaied et al. ${ }^{20}$ on the degradation of Indigo Carmine with birnessite films. The total decoloration of the indigo carmine occurs after $6 \mathrm{~h}$ contact at $\mathrm{pH} 3$. They also verified that dye degradation occurs in the presence or absence of oxygen and that some inorganic ions can be oxidized.

Influence of the dose of manganese oxide on the efficiency of removal of Orange $G$ in aqueous solution

The percentages of dye removal as a function of time obtained with the different doses evaluated are shown in Figure 7. When $0.30,0.20$, and $0.08 \mathrm{~g} \mathrm{~L}^{-1}$ of oxide were used in a 60 min reaction, $95 ; 91$ and $85 \%$ of the dye, respectively, were removed using the brown birnessite (Figure 7a), while values of $98 ; 98$ and $80 \%$, respectively, were obtained for the pyrolusite (Figure 7b). These data showed that the removal of Orange $G$ did not increase significantly when a mass of manganese oxide greater than $50 \mathrm{mg}$ (corresponding to a dose of $0.20 \mathrm{~g} \mathrm{~L}^{-1}$ ) was used. 

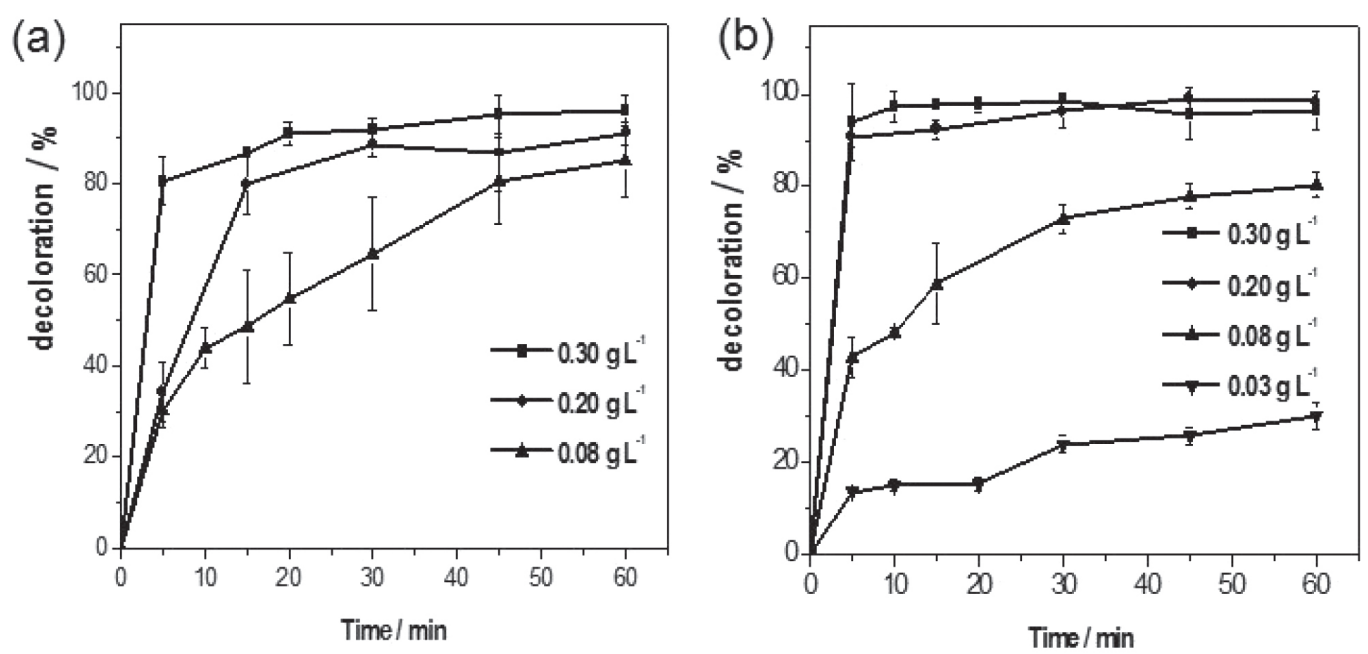

Figure 7. Effect of the dose of (a) brown birnessite and (b) pyrolusite on the percentage decoloration of Orange G. Conditions: $300 \mathrm{~mL}^{\circ} 10 \mathrm{mg} \mathrm{L} \mathrm{L}^{-1} \mathrm{OG}$ solution at $\mathrm{pH} 2$.

However, a higher dose increased the rate of removal, since it increased the number of active sites available. ${ }^{45}$

The oxidative degradation behavior of Orange $\mathrm{G}$ was evaluated by applying pseudo-first order and pseudo-second order kinetic models to the data shown in Figure 7. The nonlinear form of the pseudo-first order model used is shown in equation $9 .{ }^{46}$ The pseudo-second order model was used in its linearized form, shown in equation 10.

$\mathrm{C}_{\mathrm{t}}=\mathrm{C}_{0}\left[1-\exp \left(-\mathrm{k}_{1 \mathrm{obs}} \mathrm{t}\right)\right]$

$\frac{\mathrm{t}}{\mathrm{C}_{\mathrm{t}}}=\frac{1}{\mathrm{k}_{2 \mathrm{obs}} \mathrm{C}_{0}^{2}}+\frac{1}{\mathrm{q}_{\mathrm{e}}} \mathrm{t}$

In the above equations, $\mathrm{C}_{\mathrm{t}}$ is the amount of dye removed at time $\mathrm{t}, \mathrm{C}_{0}$ is the maximum amount of dye removed during the experiment, $\mathrm{k}_{\text {lobs }}\left(\mathrm{min}^{-1}\right)$ and $\mathrm{k}_{2 \mathrm{obs}}\left(\mathrm{L} \mathrm{mg}^{-1} \mathrm{~min}^{-1}\right)$ are the observed rate constants, and $\mathrm{q}_{\mathrm{e}}$ is the amount of dye removed at equilibrium.

The kinetic models analyzed presented coefficients of determination $\left(\mathrm{R}^{2}\right)$ near. The pseudo-first order model presented $\mathrm{R}^{2}$ between 0.9915-0.9630 and 0.9956-0.8630 for the different doses of brown birnessite and pyrolusite, respectively, while values of $\mathrm{R}^{2}$ in the range of 0.9999-0.9368 (birnessite brown) and 0.9999-0.8969 (pyrolusite) were presented by the pseudo-second order model. The residue graph (Figure 8) provided more information on the fit of these models, and it was observed that the kinetic model of pseudo-first order showed less variation of the results, that is, more agreement of the experimental data with the model. Compliance with the pseudo-first-order model is shown in Table 2.

\section{Conclusions}

Nanostructures of black and brown birnessite manganese oxide were successfully produced. Characterization of the materials confirmed their identities and revealed only morphological differences. A commercial $\mathrm{MnO}_{2}$ sample showed characteristics of pyrolusite manganese oxide. The birnessite and pyrolusite oxides presented structures with layers (from $\mathrm{Mn}^{\mathrm{III}} / \mathrm{Mn}^{\mathrm{IV}} \mathrm{O}_{6}$ octahedra) and tunnels (from $\mathrm{Mn}^{\mathrm{IV}} \mathrm{O}_{6}$ octahedra), respectively. Both materials were effective in rapid oxidative degradation of Orange $G$ dye in water, without the aid of UV, IR, temperature increase, microwaves, or ultrasound. Small doses of $\mathrm{MnO}_{2}\left(0.20 \mathrm{~g} \mathrm{~L}^{-1}\right)$ in the form of brown birnessite or pyrolusite were sufficient to remove about 90 and $99 \%$ of the dye, respectively, in a short agitation time of $30 \mathrm{~min}$. The decoloration of the dye followed pseudo-first order kinetics. The $\mathrm{pH}$ of the solution

Table 2. Pseudo-first order kinetic parameters for the degradation of Orange G

\begin{tabular}{|c|c|c|c|c|c|}
\hline \multirow{2}{*}{ Dose / $\left(\mathrm{g} \mathrm{L}^{-1}\right)$} & \multicolumn{2}{|c|}{ Brown birnessite } & \multirow{2}{*}{ Dose / $\left(\mathrm{g} \mathrm{L}^{-1}\right)$} & \multicolumn{2}{|c|}{ Pyrolusite } \\
\hline & $\mathrm{K}_{\text {lobs }} / \mathrm{min}^{-1}$ & $\mathrm{R}^{2}$ & & $\mathrm{~K}_{\text {lobs }} / \min ^{-1}$ & $\mathrm{R}^{2}$ \\
\hline 0.30 & $0.4075 \pm 0.0574$ & 0.9915 & 0.20 & $0.5600 \pm 0.0977$ & 0.9956 \\
\hline 0.20 & $0.1144 \pm 0.0142$ & 0.9878 & 0.08 & $0.1131 \pm 0.0173$ & 0.9643 \\
\hline 0.08 & $0.0618 \pm 0.0096$ & 0.9630 & 0.03 & $0.0663 \pm 0.0232$ & 0.8630 \\
\hline
\end{tabular}

$\mathrm{K}_{\text {lobs }}$ : pseudo-first order rate constant observed; $\mathrm{R}^{2}$ : coefficient of determination. 

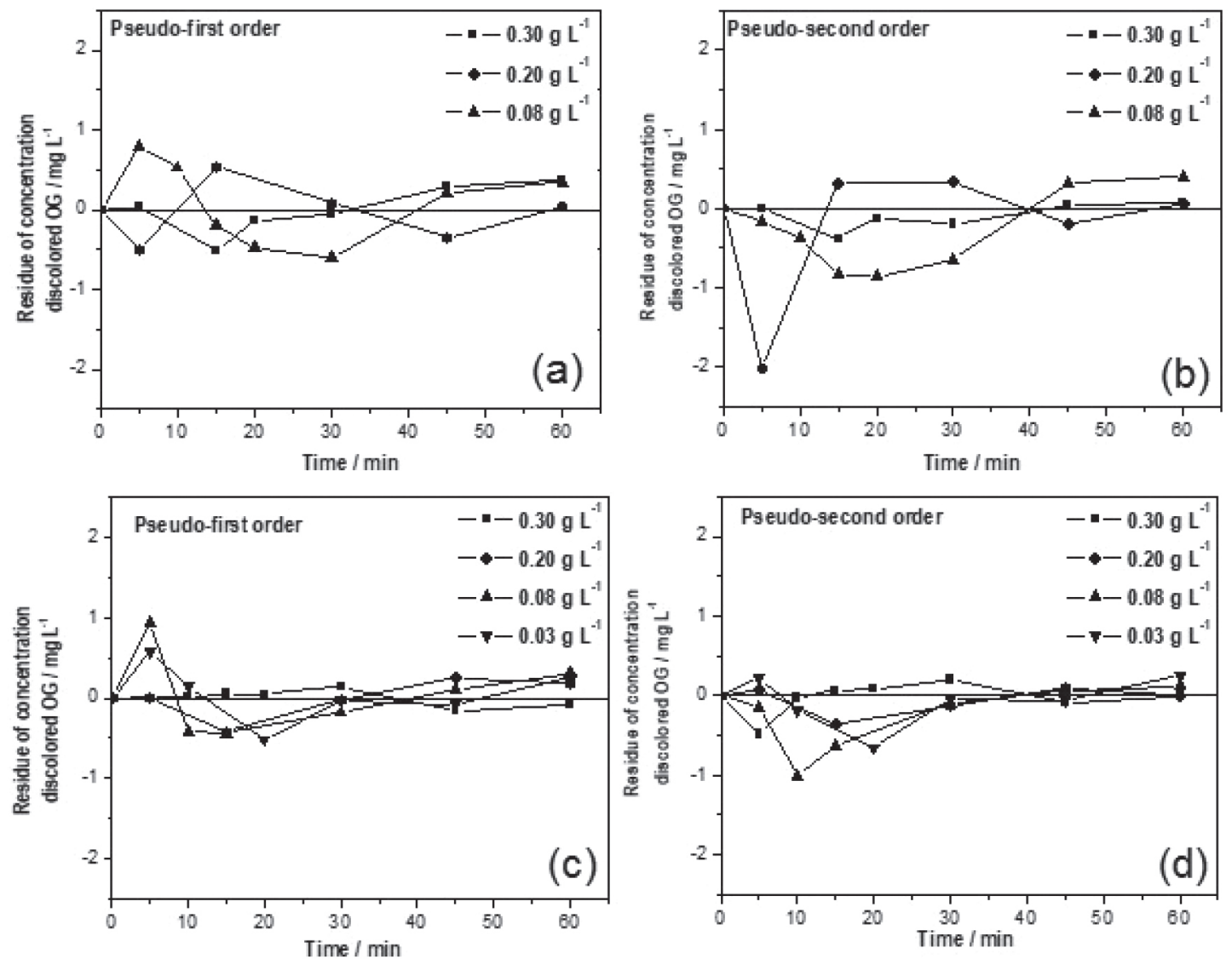

Figure 8. Residues of the fitted kinetic models for the decoloration of OG (10 $\left.\mathrm{mg} \mathrm{L}^{-1}\right)$ using different doses of (a, b) brown birnessite and (c, d) pyrolusite.

had a significant effect on the amount of dye removed, with efficient removal obtained in a strongly acidic medium $(\mathrm{pH} 2)$. These manganese oxides are promising candidates for application in the treatment of water contaminated with OG. The findings highlighted the commercial $\mathrm{MnO}_{2}$, which has been little investigated and provided satisfactory results with economy of both cost and time.

\section{Acknowledgments}

Financial support for this work was provided by the following Brazilian agencies: Foundation for Research Support of the State of Minas Gerais (FAPEMIG); National Council for Scientific and Technological Development (CNPq, 409899/2016-0); and Coordination for Improvement of Higher Education Personnel (CAPES).

The authors thank Dr Sukarno O. Ferreira for X-ray measurements, Dr Renê C. da Silva for SEM assistance and Department of Soils of Universidade Federal de Viçosa for BET surface measurements.

\section{References}

1. Feng, Q.; Kanoh, H.; Ooi, K.; J. Mater. Chem. 1999, 9, 319.
2. Kang, L.; Zhang, M.; Liu, Z.-H.; Ooi, K.; Spectrochim. Acta, Part A 2007, 67, 864.

3. Cheney, M. A.; Bhowmik, P. K.; Moriuchi, S.; Villalobos, M.; Qian, S.;Joo, S. W.; J.Nanomat. 2008, DOI 10.1155/2008/168716.

4. Zhang, L.; Nie, Y.; Hu, C.; Hu, X.; J. Hazard. Mater. 2011, 190 , 780 .

5. Gaillot, A.-C.; Lanson, B.; Drits, V. A.; Chem. Mater. 2005, 17, 2959.

6. Liu, L.; Tian, H.; He, J.; Wang, D.; Yang, Q.; J. Environ. Sci. 2012, 24, 1117.

7. Jiang, W.-T.; Chang, P.-H.; Wang, Y.-S.; Tsai, Y.; Jean, J.-S.; Li, Z.; Int. J. Environ. Sci. Technol. 2015, 12, 1695.

8. Figueira, B. A. M.; Angélica, R. S.; Scheller, T.; Cerâmica 2008, 54, 193.

9. Zhou, J.; Yu, L.; Sun, M.; Yang, S.; Ye, F.; He, J.; Hao, Z.; Ind. Eng. Chem. Res. 2016, 52, 9586.

10. Zhou, J.; Yu, L.; Sun, M.; Ye, F.; Lan, B.; Diao, G.; He, J.; J. Solid State Chem. 2013, 198, 371.

11. McKenzie, R. M.; Mineral. Mag. 1971, 38, 493.

12. Cheney, M. A.; Bhowmilk, P. K.; Qian, S.; Joo, S. W.; Hou, W.; Okoh, J. M.; J. Nanomater. 2008, DOI 10.1155/2008/763706.

13. Xia, C.; Lv, G.; Mei, L.; Song, K.; Li, Z.; Wang, X.; Xing, X.; Xu, B.; Water, Air, Soil Pollut. 2014, 225, DOI 10.1007/s11270014-2131-6. 
14. Matern, K.; Mansfeldt, T.; Appl. Clay Sci. 2015, 108, 78.

15. Ettler, V.; Knytl, V.; Komárek, M.; Puppa, L. D.; Bordas, F.; Mihaljevic, M.; Klementová, M.; Sebek, O.; Geoderma 2014, 214,2 .

16. Wang, M.; Pang, P.; Koopal, L. K.; Qiu, G.; Wang, Y.; Liu, F.; Mater. Chem. Phys. 2014, 148, 1149.

17. Ghaly, M.; El-Dars, F. M. S. E.; Hegazy, M. M.; Rahman, A.; Chem. Eng. J. 2016, 284, 1373.

18. Qin, M.; Zhao, H.; Yang, W.; Zhou, Y.; Li, F.; RSC Adv. 2016, 6, 23905.

19. Chen, H.; He, J.; Zhang, C.; He, H.; J. Phys. Chem. C 2007, $111,18033$.

20. Zaied, M.; Peulon, S.; Bellakhal, N.; Desmazières, B.; Chaussé, A.; Appl. Catal., B 2011, 101, 441.

21. Št’astný, M.; Štengl, V.; Henych, J.; Tolasz, J.; Vomácka, P.; Ederer, J.; J. Mater. Sci. 2016, 51, 2634.

22. Wang, X.; Mei, L.; Xing, X.; Liao, L.; Lv, G.; Li, Z.; Wu, L.; Appl. Catal., B 2014, 160, 211.

23. Eren, E.; Gumus, H.; Sarihan, A.; Desalination 2011, 279, 75.

24. Jiang, W.-T.; Chang, P.-H.; Wang, Y.-S.; Tsai, Y.; Jean, J.-S.; Li, Z.; Krukowski, K.; J. Hazard. Mater. 2013, 250, 362.

25. Cai, M.; Su, J.; Lian, G.; Wei, X.; Dong, C.; Zhang, H.; Jin, M.; Ultrason. Sonochem. 2016, 31, 193.

26. Madhavan, J.; Grieser, F.; Ashokkumar, M.; Ultrason. Sonochem. 2010, 17, 338.

27. Cai, M. Q.; Wei, X. Q.; Song, Z. J.; Jin, M. C.; Ultrason. Sonochem. 2015, 22, 167.

28. Lachheb, H.; Puzenat, E.; Houas, A.; Ksibi, M.; Elaloui, E.; Guillard, C.; Herrmann, J.-M.; Appl. Catal., B 2002, 39, 75.

29. Sun, J.; Wang, X.; Sun, J.; Sun, R.; Sun, S.; Qiao, L.; J. Mol. Catal. A: Chem. 2006, 260, 241.

30. Tagliaferro, G. V.; Pereira, P. H. F.; Rodrigues, L. A.; da Silva, M. L. C. P.; Quim. Nova 2011, 34, 101.
31. Mustafa, S.; Zaman, M. I.; Khan, S.; J. Colloid Interface Sci. 2006, 301, 370.

32. Cullity, B. D.; Elements of X-Ray Diffraction; Addison-Wesley Publishing Co.: Reading, USA, 1980.

33. Gonçalves, M.; de Castro, C. S.; Oliveira, L. C. A.; Guerreiro, M. C.; Quim. Nova 2009, 32, 1723.

34. Lee, C.-Y.; Kim, T.; Komarneni, S.; Han, S.-K; Cho, Y.; Appl. Clay Sci. 2013, 83, 263.

35. Zhang, S.-J.; Yu, H.-Q.; Zhao, Y.; Water Res. 2005, 39, 839.

36. Zhang, R.; He, Q.; Huang, Y.; Wang, X.; Arch. Biochem. Biophys. 2016, 596, 1.

37. Feng, W.; Nansheng, D.; Helin, H.; Chemosphere 2000, 41, 1233.

38. Zhang, Y.; Gao, F.; Wanjala, B.; Cernigliaro, G.; Gu, Z.; Appl. Catal., B 2016, 199, 504.

39. Zhong, X.; Royer, S.; Zhang, H.; Huang, Q.; Luojing, X.; Valange, S.; Barrault, J.; Sep. Purif. Technol. 2011, 80, 163.

40. Cai, M.; Su, J.; Zhu, Y.; Wei, X.; Jin, M.; Zhang, H.; Dong, C.; Wei, Z.; Ultrason. Sonochem. 2016, 28, 302.

41. Saha, S.; Pal, A.; Sep. Purif. Technol. 2014, 134, 26.

42. Dang, T. D.; Banerjee, A. N.; Cheney, M. A.; Qian, S.; Joo, S. W.; Min, B. K.; Colloids Surf., B 2013, 106, 151.

43. Dang, T. D.; Banerjee, A. N.; Tran, Q. T.; Roy, S.; J. Phys. Chem. Solids 2016, 98, 50.

44. Ismail, M.; Khan, H. M.; Sayed, M.; Cooper, W. J.; Chemosphere 2013, 93, 645.

45. Mahamallik, P.; Saha, S.; Pal, A.; Chem. Eng. J. 2015, 276, 155. 46. Simonin, J.-P.; Chem. Eng. J. 2016, 300, 254.

Submitted: January 29, 2019

Published online: May 7, 2019 